\title{
PENERAPAN SPI-COSO ATAS PEMBERIAN KREDIT DANA BERGULIR KOTAKU
}

\author{
Dheo Rimbano \\ Sekolah Tinggi Ilmu Ekonomi Musi Rawas (STIE MURA) Lubuklinggau \\ Email : rimbanodheo@gmail.com
}

\begin{abstract}
"Kota Tanpa Kumuh" (KOTAKU) program is an advanced program of National Community Empowerment Program of Urban Mandiri that has accelerated program for handling urban slums and reducing poverty and so KOTAKU provides access to financial services for poor households by market - based micro loans with many activities which generate income that usually don't have any access to other loan sources, to improve their economic conditions and activities those support economic growth and micro business, besides that teach them in managing loans and use it correctly.nevertheless, KOTAKU isn't micro finance program, KOTAKU role only builds sustainable basic solutions for loan services and non - loan services at the "kelurahan" level. This research goal is to describe whether internal control system credit application applied to KOTAKU has been in accordance with the elements of internal control based on Committee Of Sponsoring Organizations (COSO). The method was used in this research is qualitative method, qualitative method is usually called as naturalistic research method because the research was conducted in the natural conditions, it's also called as ethnography method, because in the beginning, this method is more widely used for research in cultural anthropology, it's called as qualitative research because data have been collected and its analysis is more qualitative. The finding results is rolling loan lending system that is conducted by KOTAKU has completed internal controlling aspects based on COSO, except control activities components in the elements of separation of duties, namely lending isn't separate from the loan inspection, and supervision component on the element of internal auditing that is internal which is not separate by LKM. And the recommendation can be given those are (1) giving and checking loans, and (2) internal auditing should be separated by LKM officer so that there is no collusion and irregulaties.
\end{abstract}

Keywords : SPI, Committee Of Sponsoring Organizations (COSO), Bad credit, KOTAKU (Program Kota Tanpa Kumuh)

\section{PENDAHULUAN}

\section{Latar Belakang Masalah}

Dalam kehidupan sehari-hari, kata kredit bukan merupakan kata yang asing bagi masyarakat kita. Perkataan kredit tidak saja dikenal oleh masyarakat di kota-kota besar, tetapi sampai keperdesaaan kata kredit tersebut sudah sangat popular Istilah kredit berasal dari bahasa Yunani credere yang berarti kepercayaan oleh karena itu, dasar dari kredit adalah kepercayaan. Seseorang atau suatu badan yang memberikan kredit (kreditor) percaya bahwa penerima kredit (debitur) pada masa yang akan datang akan sanggup memenuhi segala sesuatu yang telah disajikan. Apa yang disajikan itu dapat berupa barang, uang, atau jasa. (Abdullah dan Tantri, 2014:162). 
Dengan semakin meningkatnya kredit, disertai pula dengan meningkatnya kredit bermasalah atau kredit macet atas kredit yang diberikan. Bahaya yang timbul dari kredit macet adalah tidak terbayarnya kembali kredit tersebut, baik sebagian maupun seluruhnya, oleh karena itu diperlukan suatu pengendalian intern dan sistem pemberian kredit yang baik agar kredit yang disalurkan berjalan dengan efektif dan terhindar dari kredit yang bermasalah. Menurut Diana dan Setiawati (2011:82) Pengendalian intern adalah rencana organisasional, metode, dan pengukuran yang dipilih oleh suatu kegiatan usaha untuk mengamankan harta kekayaannya, mengecek keakuratan dan keandalan data akuntansi usaha tersebut, meningkatkan efesiensi operasional, dan mendukung dipatuhinya kebijakan manajerial yang telah ditetapkan.

Program Kota Tanpa Kumuh (KOTAKU) merupakan program lanjutan dari Program Nasional Pemberdayaan Masyarakat (PNPM) Mandiri Perkotaan yang memiliki program percepatan penanganan pemukiman kumuh perkotaan dan mengurangi kemiskinan serta KOTAKU juga menyediakan akses layanan keuangan kepada rumah tangga miskin dengan pinjaman mikro berbasis pasar dengan kegiatan yang menghasilkan pendapatan yang biasanya tidak memiliki akses ke sumber pinjaman lainnya, untuk memperbaiki kondisi ekonomi mereka dan kegiatan yang mendukung tumbuhnya ekonomi serta usaha mikro disamping itu membelajarkan mereka dalam hal mengelola pinjaman dan menggunakannya secara benar. Meskipun demikian, KOTAKU bukanlah program keuangan mikro. Peran KOTAKU hanya membangun dasar dasar solusi yang berkelanjutan untuk jasa pinjaman dan non pinjaman di tingkat kelurahan.

Program KOTAKU dijadikan momen untuk tahap konsolidasi kegiatan keuangan mikro. Oleh sebab itu, dalam tahap ini perlu diciptakan Unit Pengelola Keuangan (UPK) yang kuat, sehat dan secara operasional terpisah dari Lembaga Keswadayaan Masyarakat (LKM). Namun dalam pemberian kredit ada oknum UPK yang tidak menerapkan sistem pengendalian intern yang diterapkan oleh KOTAKU, ada kebijakan pinjaman bergulir yang tidak dilalui sepenuhnya oleh beberapa UPK yaitu sasaran, prinsip-prinsip dan strategi dalam pemberian pinjaman bergulir pada KOTAKU misalnya memberikan pinjaman tidak mengikuti prosedur pemberian pinjaman bergulir yang ditetapkan hanya karena sanak saudara, memberikan pinjaman tidak sesuai sasaran yaitu minimal $30 \%$ peminjam adalah perempuan, memberikan pinjaman kepada rumah tangga yang tidak berasal dari rumah tangga miskin, petugas UPK yang tidak mendapatkan pengawasan yang baik oleh pengawas UPK, petugas UPK yang tidak mempunyai kemampuan dalam pengelolaan kredit dan tidak mengikuti pelatihan dasar yang diadakan oleh KOTAKU, dan pembentukan UPK baru tanpa mengikuti kebijakan dan prosedur lengkap itulah beberapa penyebab terjadinya kredit bermasalah atau kredit macet pada dana bergulir KOTAKU.

Tabel 1: Kredit Berdasarkan Kolektibilitas Pinjaman di Kecamatan Lubuklinggau Timur I Tahun 2013-2016

\begin{tabular}{|c|c|c|c|c|c|c|c|c|c|c|}
\hline & & & 2013 & & 2014 & & 2015 & & 2016 & \\
\hline No & Kecamatan & Keterangan & KSM & $\%$ & KSM & $\%$ & KSM & $\%$ & KSM & $\%$ \\
\hline \multirow[t]{5}{*}{1} & Majapahit & Lancar & & & 8 & 14,8 & 18 & 35,3 & 18 & 32,7 \\
\hline & & DPK & & & & & & & & \\
\hline & & Kurang lancer & & & & & & & & \\
\hline & & Diragukan & & & & & & & & \\
\hline & & Macet & & & & & & & & \\
\hline \multirow[t]{5}{*}{2} & Niken jaya & Lancar & 15 & 65,2 & 15 & 27,8 & 4 & 7,8 & 3 & 5,5 \\
\hline & & DPK & & & & & 4 & 7,8 & & \\
\hline & & Kurang lancer & 4 & 17,4 & 8 & 14,8 & 3 & 5,9 & 7 & 12,7 \\
\hline & & Diragukan & & & & & & & & \\
\hline & & Macet & 4 & 17,4 & & & 5 & 9,8 & & \\
\hline \multirow[t]{4}{*}{3} & Taba jemekeh & Lancar & & & 3 & 5,6 & 6 & 11,8 & 3 & 5,5 \\
\hline & & DPK & & & & & & & 14 & 25,5 \\
\hline & & Kurang lancer & & & 12 & 22,2 & 11 & 21,6 & & \\
\hline & & Diragukan & & & & & & & 2 & 3,6 \\
\hline
\end{tabular}




\begin{tabular}{|l|l|l|l|l|l|l|l|l|l|l|}
\hline & Macet & & & & & & & & \\
\hline 4 & Batu urib & Lancar & & & 5 & 9,3 & & & 6 & 10,9 \\
\hline & DPK & & & 1 & 1,8 & & & & \\
\hline & Kurang lancer & & & 2 & 3,7 & & & 2 & 3,6 \\
\hline & & Diragukan & & & & & & & & \\
\hline & Macet & & & & & & & & \\
\hline & Total & 23 & 100 & 54 & 100 & 51 & 100 & 55 & 100 \\
\hline
\end{tabular}

Sumber : KOTAKU Lubuklinggau 2018

Dari tabel tersebut dapat dilihat bahwa kegiatan kredit pada pinjaman dana bergulir KOTAKU dikecamatan Lubuklinggau Timur I mengalami masalah, dari delapan yang ada hanya ada empat kelurahan yang mendapatkan pinjaman dana bergulir yaitu kelurahan Majapahit, Nikan Jaya, Taba Jemekeh, dan Batu Urib Taba, sedangkan kelurahan Taba Koji, Watervang, Air Kuti, dan Taba Lestari tidak mendapatkan pinjaman dana bergulir lagi semenjak tahun 2010 karena pada kelurahan itu berkolektibitas macet. Maka dalam sistem pemberian kredit pinjaman bergulir para UPK KOTAKU harus melaksanaan pemberian kredit yang benar untuk para Kelompok Swadaya Masyarakat (KSM) yang sesuai dengan sistem pengendalian intern pemberian kredit yang ada pada KOTAKU dan unsur-unsur dalam Committee Of Sponsoring Organizations (COSO) agar pemberian kredit pinjaman bergulir KOTAKU efektif.

\section{Rumusan Masalah}

Apakah sistem pengendalian intern pemberian kredit yang diterapkan pada KOTAKU sudah sesuai dengan unsur-unsur pengendalian intern menurut Committee of Sponsoring Organizations (COSO)?

\section{Manfaat Penelitian}

a. Mengembangkan ilmu pengetahuan khususnya tentang pemberian kredit dana bergulir dari program KOTAKU kepada UKM sebagai upaya untuk mengurangi tingkat kemiskinan.

b. Hasil penelitian ini diharapkan dapat digunakan sebagai bahan acuan untuk membantu pengambilan keputusan yang berkaitan dengan pemberian kredit dana bergulir.

c. Hasil penelitian ini diharapkan dapat memberikan informasi mengenai pengendalian intern, khusus nya mengenai sistem pemberian kredit dan diharapkan penelitian ini juga menjadi sebuah referensi bagi mahasiswa

d. Penelitian ini merupakan kesempatan bagi peneliti untuk menambah pengetahuan mengenai sistem pengendalian intern atas prosedur pemberian kredit.

\section{KAJIAN PUSTAKA}

\section{Prinsip-Prinsip Aktivitas Pengendalian Internal}

Menurut COSO dalam Krismiaji (2015:255) Salah satu komponen pengendalian internal menurut $\mathrm{COSO}$ adalah aktivitas pengendalian. Aktivitas pengendalian menunjukkan usaha perusahaan untuk mengidentifikasi resiko yang sedang dihadapi, seperti kecurangan(fraud).

Ada 7 prinsip dari aktivitas pengendalian, antara lain: (a) Otorisasi transaksi dan aktivitas yang tepat; (b) Pemisahan tugas ; (c) Pengendalian pengembangan sistem dan perolehan system; (d) Pengendalian manajemen perubahan; (e) Perancangan dan pengunaaan dokumen yang memadai; (f) Penjagaan aset, catatan dan data; (g) Pengecekan independen terhadap kinerja

\section{Fungsi dan tujuan}

Menurut Committee Of Sponsoring Organizations (COSO) dalam Diana dan Anastasia (2011:83) pengendalian intern memiliki tujuan, yaitu : (a) Efektivitas dan efisiensi operasi; (b) Daya andal pelaporan keuangan; (c) Kesesuaian dengan aturan dan regulasi yang ada. 


\section{Metode Penyelamatan Kredit Macet}

Menurut Abdullah dan Tantri (2014:180) dan Menurut Kasmir (2016:149) Metode yang digunakan untuk penyelamatan kredit macet dilakukan dengan cara sebagai berikut: (a) Rescheduling; (b) Reconditioning; (c) Restructuring; (d) Kombinasi; (e) Penyitaan jaminan.

\section{Prosedur pengendalian intern}

Menurut Sujarweni (2015:74) kegiatan pengendalian adalah suatu tindakan yang dibutuhkan untuk mengatasi resiko. Pada kegiatan ini antara lain menetapkan pelaksanaan prosedur kebijakan yang sudah dibuat serta memastikan apakah tindakan untuk mengatasi resiko sudah dilaksanakan dengan efektif dan efesien. Berikut secara singkat prosedur yang harus dilakukan : (a) Pemberian otorisasi atas transaksi dan kegiatan; (b) Pembagian tugas dan tanggung jawab; (c) Dokumen yang akan digunakan sebaiknya dirancang terlebih dahulu; (d) Perlindungan yang cukup ketat terhadap kekayaan dan catatan perusahaan ; (e) Pemeriksaan terhadap kinerja perusahaan.

\section{Indikator}

Menurut COSO dalam Diana dan Setiawati (2011:83-92) Indikator pengendalian internal yaitu :

1) Lingkungan Pengendalian

2) Penaksiran Risiko

3) Aktivitas Pengendalian

4) Informasi dan Komunikasi

5) Pemantauan Kinerja

\section{Faktor-faktor yang mempengaruhi pengendalian intern:}

Menurut Kasmir (2015:213) Tujuan dilakukannya pengendalian intern adalah untuk mencegah timbulnya kerugian bagi sebuah organisasi, yang timbul antara lain karena faktor-faktor sebagai berikut :

a) Penggunaan sumber daya yang tidak efisien dan boros

b) Keputusan manajemen yang tidak baik

c) Kesalahan yang tidak disengaja dalam pencatatan dan pemerosesan data

d) Kehilangan atau kerusakan catatan secara tidak sengaja

e) Kehilangan aktiva karena kecerobohan karyawan

f) Tidak ditaatinya kebijakan manajemen dan peraturan lainnya oleh para karyawan

g) Perubahan secara tidak sah terhadap SIA atau komponen-komponen lainnya.

\section{Faktor-faktor yang mempengaruhi dalam pemberian kredit:}

Menurut Abdullah dan Tantri (2014:165) kredit yang diberikan oleh suatu lembaga perbankan didasarkan atas : (a) Kepercayaan; (b) Kesepakatan; (c) Jangka waktu; (d) Resiko; dan (e) Balas jasa.

\section{Keterkaitan sub-sub Fokus}

Pengendalian intern berdasarkan COSO dalam pemberian kredit sangat berkaitan, pinjaman dana bergulir akan lebih efektif apabila penegendalian intern dibangun dalam infastruktur KOTAKU. Salah satu sektor pontensial yang mendapatkan perhatian dan perlu dikembangkan adalah sektor usaha kecil dan menengah, namun sektor ini umumnya menghadapi masalah dalam aspek permodalan. KOTAKU dalam hal ini berperan dalam hal membantu sektor usaha kecil dan menengah melalui pemberian kredit, tetapi dalam pemberian kredit ada masalah keamanan yang harus diperhatikan. Maka peranan pengendalian intern dalam menunjang efektivitas pemberian kredit tidak dapat diabaikan dan harus di selenggarakan pengendalian intern yang baik dalam pemberian kredit dana bergulir KOTAKU. Pengendalian intern berdasarkan COSO yang baik diperoleh dari struktur yang terkoordinasi yang berguna bagi perusahaan/organisasi untuk menyusun 
laporan keungan yang lebih teliti, mencegah kecurangan, serta mengamankan harta. Lembaga yang langsung mengelola kegiatan pinjaman bergulir adalah Unit Pengelola Keuangan (UPK), UPK adalah salah satu unit pengelola dari tiga unit pengelola yang berada dibawah Lembaga Keswadayaan Masyarakat (LKM). Dua unit lainnya adalah Unit Pengelola Lingkungan (UPL) dan Unit Pengelola Sosial (UPS).

\section{Hasil Penelitian yang Relevan}

Tabel 2: Penelitian yang relevan

\begin{tabular}{|c|c|c|}
\hline Penulis & Judul Penelitian & Hasil Penelitian \\
\hline $\begin{array}{l}\text { Hairun Nisa } \\
2017\end{array}$ & $\begin{array}{l}\text { Analisis } \text { sistem } \\
\text { penengendalian } \\
\text { intern persetujuan } \\
\text { kredit } \quad \text { dalam } \\
\text { memperkecil resiko } \\
\text { piutang tak tertagih } \\
\text { padar PT.Nusa } \\
\text { Suryadana Cabang } \\
\text { Martapura }\end{array}$ & $\begin{array}{l}\text { Hasil Penelitian bahwa pengendalian intern persetujuan kredit dalam } \\
\text { memperkecil resiko piutang tak tertagih pada PT.Nusa Surya Ciptadana } \\
\text { Martapura selama ini masih belum sesuai dengan prinsip akuntansi } \\
\text { berterima umum. Perusahaan seharusnya memisahkan fungsi penugasan } \\
\text { dengan fungsi wewenang dan fungsi otorisasi, untuk menghindari } \\
\text { kecurangan yang dilakukan karyawan karena berada difungsi yang } \\
\text { sama,seharusnya sebelum menyetujui pengajuan kredit nasabah survey } \\
\text { harus memperoleh otorisasi oleh fungsi kredit yakni kepala cabang \& } \\
\text { kepala surveyor. }\end{array}$ \\
\hline $\begin{array}{l}\text { Yesti } \\
\text { Nawangsari } \\
\text { Iwan Setya } \\
\text { Putra } \\
2016\end{array}$ & $\begin{array}{lr}\text { Analisis } & \text { sistem } \\
\text { pengendalian } & \text { intern } \\
\text { pemberian kredit } \\
\text { dalam menurunkan } \\
\text { tingkat kredit macet } \\
\text { pada r koperasi } \\
\text { simpan pinjam } \\
\text { Kharisma } \\
\text { Karya }\end{array}$ & $\begin{array}{l}\text { Penerapan sistem pengendalian intern pemberian kredit pada Koperasi } \\
\text { Simpan Pinjam Kharisma Mitra Karya kurang efektif, hal tersebut terlihat } \\
\text { dari hasil survei dimana prinsip-prinsip pemberian kredit yang sudah ada } \\
\text { dalam lembaga kurang diterapkan dengan baik, persetujuan kredit belum } \\
\text { dilakukan secara tertulis dan jelas serta pemisahan fungsi dan tugas pada } \\
\text { struktur organisasi yang kurang jelas. penulis memberikan saran } \\
\text { mengefektifkan pencatatan atau persetujuan secara tertulis pada hasil } \\
\text { survei dan memberikan kejelasan pada fungsi dan tugas dalam struktur } \\
\text { organisasi }\end{array}$ \\
\hline $\begin{array}{l}\text { Nesti Angelica, } \\
\text { Hendry Jaya } \\
\text { dan Rizki Eka } \\
\text { Putra (2016) }\end{array}$ & $\begin{array}{l}\text { Analisis sistem } \\
\text { pengendalian } \\
\text { internal pada proses } \\
\text { pemberian kredit di } \\
\text { PT. Bank Rakyat } \\
\text { Indonesia Tbk } \\
\text { Cabang Batam }\end{array}$ & $\begin{array}{l}\text { Lingkungan pengendalian (Control Environment), suasana organisasi yang } \\
\text { mempengaruhi kesadaran penguasaan dari seluruh pegawainya. Penaksiran } \\
\text { resiko (risk assestment), adalah proses mengidentifikasi dan menilai } \\
\text { resiko-resiko yang dihadapi dalam mencapai tujuan setelah teridentifikasi, } \\
\text { manajemen harus menentukan bagaimana mengelola atau } \\
\text { mengendalikannya. Aktivitas pengendalian (control aktivities), adalah } \\
\text { kebijakan dan prosedur yang harus ditetapkan untuk meyakinkan } \\
\text { manajemen bahwa semua arahan telah dilaksanakan. Aktivitas } \\
\text { pengendalian ini diterapkan pada semua tingkat organisasi dan pengolahan } \\
\text { data. Informasi dan komunikasi (information and communication), dua } \\
\text { elemen yang dapat membantu manajemen melaksanakan tanggung } \\
\text { jawabnya. Pemantauan (monitoring), suatu proses penilaian sepanjang } \\
\text { waktu atas kualitas pelaksanaan pengendalian internal dan dilakukan } \\
\text { perbaikan jika dianggap perlu. }\end{array}$ \\
\hline
\end{tabular}

Sumber : Dari Berbagai Jurnal, 2018

\section{METODOLOGI PENELITIAN Rancangan Penelitian}

Menurut Sujarweni (2015:26) rancangan penelitian/desain penelitian adalah suatu rencana tentang bagaimana menggumpulkan dan mengelolah data agar penelitian yang diharapkan dapat tercapai. Penelitian ini mempunyai fokus penelitian yaitu sistem pengendalian intern sedangkan sub fokus penelitian yaitu sistem pengendalian intern atas pemberian kredit dana bergulir KOTAKU, permasalahan yang ada pada program KOTAKU salah satunya adalah kredit macet pada pinjaman bergulir yang penyebab permasalahan nya yaitu memberikan kerdit pada pinjaman bergulir UPK tidak menerapkan semua sistem pengendalian intern pemberian kredit KOTAKU ada kebijakan pinjaman yang tidak diperhatikan seperti memberikan kredit dana bergulir tidak melalui survey hanya karena sanak saudara, memberikan pinjaman tidak sesuai sasaran yaitu minimal $30 \%$ peminjam adalah perempuan, memberikan pinjaman kepada rumah tangga yang tidak berasal dari rumah tangga miskin, petugas UPK yang tidak mendapatkan pengawasan yang baik dari pengawas UPK, petugas UPK yang tidak 
mempunyai kemampuan dalam pengelolaan kredit dan tidak mengikuti pelatihan dasar yang diadakan oleh KOTAKU, dan pembentukan UPK baru tanpa mengikuti kebijakan dan prosedur lengkap. Agar masalah kredit macet ini dapat berkurang UPK KOTAKU seharusnya dapat menerapkan semua sistem pengendalian intern pemberian kredit dana bergulir yang ada pada KOTAKU dan sesuai dengan unsur-unsur dalam Committee of Sponsoring Organizations (COSO).

\section{Metode Penelitian}

Menurut Sugiyono (2013:2) metode penelitian merupakan cara ilmiah untuk mendapatkan data dengan tujuan dan kegunaan tertentu. Metode yang digunakan dalam penelitian ini yaitu metode kualitatif, metode penelitian kualitatif sering disebut metode penelitian naturalistik karena penelitiannya dilakukan pada kondisi yang alamiah, disebut juga sebagai metode etnografi, karena pada awalnya metode ini lebih banyak digunakan untuk penelitian bidang antropologi budaya, disebut sebagai metode kualitatif karena data yang terkumpul dan analisisnya lebih bersifat kualitatif.

\section{Prosedur Penelitian}

Dengan mengadopsi Sujarweni (2015:30) Tahap-tahap penelitian kualitatif yaitu:

1) Tahap pra lapangan : Dengan menyiapkan rancangan penelitian, mengurus perijinan dan perlengkapan untuk penelitian.

2) Tahap lapangan, Menggumpulkan data-data dengan mewawancarai UPK dan menggumpulkan dokumen-dokumen yang ada pada fasilitator kelurahan (FASKEL) KOTAKU.

3) Tahap pengelolahan data, Mengelola data yang diperoleh dari UPK dan FASKEL yang kemudian disusun dalam sebuah penelitian.

\section{Prosedur Analisis Data}

Analisis data pada penelitian ini menggunakan versi Miles dan Huberman dalam Sugiyono (2013:246).

\section{Analisis sebelum di lapangan}

Penelitian kualitatif telah melakukan analisis data sebelum peneliti memasuki lapangan. Analisis dilakukan terhadap data hasil studi pendahuluan, atau data sekunder, yang akan digunakan untuk menentukan fokus penelitian. Namun fokus penelitian ini masih bersifat sementara, dan akan berkembang setelah peneliti masuk dan selama di lapangan. Dari hasi pendahuluan dengan melihat adanya masalah pada kredit yang diberikan UPK KOTAKU untuk para peminjam dikecamatan Lubuklinggau Timur I, berdasarkan masalah itu diduga bahwa pengendalian intern pada KOTAKU tidak baik.

\section{Analisis data di lapangan model Miles and Huberman}

1) Reduksi data (data reduction).

Karena banyaknya data yang diberikan Fasilitator Kelurahan (FASKEL) dan Unit Pengelola Keuangan (UPK) saya harus memilih hal-hal yang pokok dan hanya memfokuskan pada data yang saya gunakan untuk penelitian saya agar mempermudah dalam melakukan pengumpulan data selanjutnya.

2) Penyajian data (data display)

Mendisplaykan faktor-faktor apa saja yang menyebabkan kredit pinjaman bergulir yang diberikan Unit Pengelolah Keuangan KOTAKU mengalami masalah, sebabsebab itu ditemukan dengan cara mewawancarai Unit Pengelola Keuangan (UPK).

3) Penarikan kesimpulan (verification)

Pada tahap verification ini, peneliti melakukan penarikan kesimpulan yaitu: Sistem pengendalian intern yang ada pada KOTAKU tidak diterapkan oleh sebagian UPK yang ada pada kelurahan itu, sehingga terjadinya masalah kredit macet pada pinjaman bergulir yang ada pada KOTAKU. Tetapi kesimpulan ini masih bersifat sementara dan akan berubah apabila tidak ditemukan bukti-bukti yang kuat yang mendukung pada 
tahap pengumpulan data berikutnya. Tetapi apabila kesimpulan yang dikemukakan pada tahap awal didukung oleh bukti-bukti yang valid dan dibenarkan oleh para Kelompok Swadaya Masyarakat (KSM), Unit Pengelola Keuangan (UPK), dan Fasilitator Kelurahan yang ada pada kecamatan Lubuklinggau Timur I, maka kesimpulan yang dikemukakan merupakan kesimpulan yang kredibel.

\section{HASIL PENELITIAN}

\section{Pengendalian Intern Pemberian Kredit Dana Bergulir oleh UPK KOTAKU Kebijakan pinjaman bergulir}

Supaya aktivitas kredit ini dapat berjalan dengan lancar maka diperlukannya suatu sistem kredit yang sesuai dengan ketentuan yang ada pada pinjaman bergulir agar mampu menjamin keberlangsungan kredit yang diberikan.

1) Sasaran

Sasaran utama pelaksanaan kegiatan pinjaman bergulir adalah rumah tangga miskin (berpendapatan rendah) di wilayah kelurahan/desa LKM/UPK berada, khususnya masyarakat miskin yang sudah diidentifikasi dalam daftar masyarakat miskin PS2. Indikator tercapainya sasaran tersebut meliputi:

a) Peminjam berasal dari rumah tangga miskin yang telah diidentifikasi dalam PJM Pronangkis dan telah masuk dalam Daftar PS2.

b) Minimal $30 \%$ peminjam adalah perempuan

c) Para peminjam dari rumah tangga miskin tersebut telah bergabung dalam Kelompok Swadaya Masyarakat (KSM) khusus untuk kegiatan ini beranggotakan minimal 5 orang

d) Akses pinjaman bagi KSM peminjam yang kinerja pengembaliannya baik terjamin keberlanjutannya baik melalui dana BLM maupun melalui dana hasil chanelling dengan kebijakan pinjaman yang jelas.

Berdasarkan uraian diatas dapat dilihat bahwa sasaran pinjaman bergulir adalah rumah tangga miskin dan Minimal 30\% peminjam adalah perempuan berdasarkan hasil wawancara dan data yang ditemukan dilapangan, ditemukan peminjam yang bukan berasal dari rumah tangga miskin dan pemijam perempuan yang kurang dari $20 \%$.

2) Prinsip - prinsip

Beberapa prinsip dasar dalam pemberian pinjaman bergulir yang perlu mendapat perhatian dari LKM / UPK antara lain adalah:

a) Dana BLM yang dialokasikan untuk kegiatan pinjaman bergulir adalah milik masyarakat kelurahan/desa sasaran dan bukan milik perorangan

b) Tujuan dipilihnya kegiatan pinjaman bergulir adalah dalam rangka membantu program penanggulangan kemiskinan dan oleh karenanya harus menjangkau warga masyarakat miskin sebagai kelompok sasaran utama PNPM Mandiri Perkotaan

c) Pengelolaan pinjaman bergulir berorientasi kepada proses pembelajaran untuk penciptaan peluang usaha dan kesempatan kerja, peningkatan pendapatan masyarakat miskin, serta kegiatan-kegiatan produktif lainnya;

d) Pengelolaan pinjaman bergulir dipisahkan antara LKM sebagai representasi dari warga masyarakat pemilik modal dengan UPK sebagai pengelola kegiatan pinjaman bergulir yang bertanggungjawab langsung kepada LKM.

e) Prosedur serta keputusan pemberian pinjaman harus mengikuti prosedur pemberian pinjaman bergulir standar yang ditetapkan.

f) Manajer dan Petugas UPK harus orang yang mempunyai kemampuan dan telah memperoleh sertifikat pelatihan dasar yang diadakan oleh PNPM Mandiri Perkotaan.

g) UPK telah mempunyai sistim pembukuan yang standar dan sistim pelaporan keuangan yang memadai.

h) UPK mendapat pengawasan baik oleh LKM melalui Pengawas UPK maupun konsultan pelaksana (KMW) melalui tenaga ahli dan fasilitator, atau pihak yang ditunjuk proyek 
Berdasarkan diuraikan diatas dapat dilihat prinsip-prinsip pinjaman bergulir, dari hasil wawancara dan data lapangan ditemukan informasi bahwa adanya prinsip-prinsip yang tidak diterapkan yaitu tidak adanya pemisahan tugas antara manajer UPK, UPK, dan pengawas UPK.

\section{Analisis perbandingan penerapan sistem pengendalian intern COSO dengan sistem pemberian kredit pada KOTAKU}

Pengendalian intern dalam suatu pemberian kredit pada pinjaman bergulir sangatlah penting supaya kredit yang diberikan tepat dan berguna. Dalam penelitian ini, peneliti membandingkan pengendalian intern pada sistem pemberian kredit yang dilakukan UPK KOTAKU dengan komponen yang ditetapkan COSO dalam Diana dan Setiawati ( 2011: 83-92) yaitu lingkungan pengendalian, penaksiran resiko, aktivitas pengendalian, informasi dan komunikasi, pengawasan.

Tabel 3 : Tabel analisis perbandingan pengendalian intern pinjaman bergulir KOTAKU dengan unsur-unsur pengendalian intern COSO

\begin{tabular}{|c|c|c|c|c|c|}
\hline No & $\begin{array}{l}\text { Komponen } \\
\text { dalam } \\
\text { pengendalian } \\
\text { intern COSO }\end{array}$ & $\begin{array}{l}\text { Unsur-unsur pengendalian } \\
\text { intern COSO }\end{array}$ & $\begin{array}{c}\text { Praktik pengendalian intern pada } \\
\text { KOTAKU }\end{array}$ & $\begin{array}{l}\text { Sesuai/tidak } \\
\text { sesuai }\end{array}$ & Keterangan \\
\hline \multirow[t]{7}{*}{1} & $\begin{array}{l}\text { Lingkungan } \\
\text { pengendalian }\end{array}$ & $\begin{array}{l}\text { Filosophi manajemen } \\
\text { dan gaya operasi }\end{array}$ & $\begin{array}{l}\text { Fasilitator yang mengembangkan } \\
\text { berbagai sikap positif dalam } \\
\text { berkelompok dan memantau } \\
\text { keefektifan para petugas UPK. }\end{array}$ & Sesuai & \\
\hline & & $\begin{array}{l}\text { Intregritas dan nilai } \\
\text { etika }\end{array}$ & $\begin{array}{l}\text { Setiap UPK memiliki buku pedoman } \\
\text { dalam pengelolahan pinjaman kredit } \\
\text { dana bergulir. }\end{array}$ & Sesuai & \\
\hline & & $\begin{array}{l}\text { Komitmen terhadap } \\
\text { kompetensi }\end{array}$ & $\begin{array}{l}\text { Adanya persyaratan yang harus } \\
\text { dipenuhi untk menjadi LKM, UPK, } \\
\text { pengawas UPK. }\end{array}$ & & \\
\hline & & Komite audit & $\begin{array}{l}\text { Auditor ekternal yang mengaudit } \\
\text { pinjaman bergulir yaitu "kantor } \\
\text { akuntan public Drs. Acmad Djunaidi } \\
\text { B. AK". }\end{array}$ & & \\
\hline & & Struktur organisasi & $\begin{array}{l}\text { Adanya struktur lengkap LKM yang } \\
\text { mengelolah pinjaman bergulir. }\end{array}$ & & \\
\hline & & $\begin{array}{l}\text { Metode penetapan } \\
\text { otoritas dan tanggung } \\
\text { jawab }\end{array}$ & $\begin{array}{l}\text { Adanya uraian tugas dan tanggung } \\
\text { jawab dari semua konsultan } \\
\text { KOTAKU. }\end{array}$ & & \\
\hline & & $\begin{array}{l}\text { Kebijakan dan praktik } \\
\text { sumber daya manusia }\end{array}$ & $\begin{array}{l}\text { Adanya pelatihan pada setiap UPK } \\
\text { serta rekomendasi perbaikan kinerja } \\
\text { UPK/LKM }\end{array}$ & & \\
\hline \multirow[t]{2}{*}{2} & Penaksiran risiko & $\begin{array}{l}\text { Menafsir resiko atas } \\
\text { setiap ancaman yang } \\
\text { mungkin dihadapi } \\
\text { perusahaan }\end{array}$ & $\begin{array}{l}\text { Dengan adanya monitoring } \\
\text { administratif dan monitoring } \\
\text { lapangan }\end{array}$ & Sesuai & \\
\hline & & $\begin{array}{l}\text { Memilih pengendalian } \\
\text { untuk mengatasi } \\
\text { resiko }\end{array}$ & $\begin{array}{l}\text { Melakukan penyelesaian pinjaman } \\
\text { bermasalah melalui } 3 \text { pendekatan } \\
\text { Yaitu menagih } \\
\text { tunggakan,menyelamatkan pinjaman } \\
\text { bermasalah, menagih melalui jalur } \\
\text { hukum. }\end{array}$ & Sesuai & \\
\hline \multirow[t]{4}{*}{3} & $\begin{array}{l}\text { Aktivitas } \\
\text { pengendalian }\end{array}$ & $\begin{array}{l}\text { Desain dokumen yang } \\
\text { baik dan bernomor } \\
\text { urut tercetak }\end{array}$ & $\begin{array}{l}\text { Dokumen yang bernomor urut } \\
\text { tercetak dan tempat untuk tanda } \\
\text { tangan yang berwewenang. }\end{array}$ & Sesuai & \\
\hline & & Pemisahan tugas & $\begin{array}{l}\text { Pemberi pinjaman tidak terpisah } \\
\text { dengan pemeriksa pinjaman. }\end{array}$ & Tidak sesuai & $\begin{array}{l}\text { Adanya peluang untuk } \\
\text { melakukan penyalagunaan } \\
\text { wewenang, bisa saja kredit } \\
\text { yang disalurkan tidak sesuai } \\
\text { dengan prinsip-prinsip dan } \\
\text { sasaran. }\end{array}$ \\
\hline & & $\begin{array}{l}\text { Otorisasi yang } \\
\text { memadai }\end{array}$ & $\begin{array}{l}\text { UPK memiliki wewenang untuk } \\
\text { persetujuan pemberian pinjaman atau } \\
\text { penolakan pinjaman pada KSM. }\end{array}$ & Sesuai & \\
\hline & & $\begin{array}{l}\text { Mengamankan harta } \\
\text { dan catatan }\end{array}$ & $\begin{array}{l}\text { Catatan dan dokumen nasabah yang } \\
\text { tidak diperuntukan untuk publik dan }\end{array}$ & Sesuai & \\
\hline
\end{tabular}




\begin{tabular}{|c|c|c|c|c|c|}
\hline & & perusahaan & $\begin{array}{l}\text { sekretariat LKM yang memelihara } \\
\text { catatan semua aset selalu terbarui dan } \\
\text { melakukan pengecekan secara rutin } \\
\text { untuk memastikan pengamanannya. }\end{array}$ & & \\
\hline & & $\begin{array}{l}\text { Menciptakan } \\
\text { pengecekan } \\
\text { independen atas } \\
\text { pekerjaan karyawan } \\
\text { lain }\end{array}$ & $\begin{array}{l}\text { Pengecekan independen hanya untuk } \\
\text { mengaudit pinjaman bergulir saja } \\
\text { bukan untuk mengaudit para } \\
\text { konsultan KOTAKU. }\end{array}$ & Tidak sesuai & $\begin{array}{l}\text { Pemeriksaan yang dilakukan } \\
\text { oleh auditor independen } \\
\text { sangat diperlukan karena } \\
\text { untuk melihat kenerja para } \\
\text { konsultan dan petugas UPK }\end{array}$ \\
\hline \multirow[t]{5}{*}{4} & $\begin{array}{l}\text { Informasi dan } \\
\text { Komunikasi }\end{array}$ & $\begin{array}{l}\text { Identifikasi dan catat } \\
\text { transaksi yang valid }\end{array}$ & $\begin{array}{l}\text { Setiap tahun akuntansi dan LKM } \\
\text { dibantu oleh sekretariat harus } \\
\text { menyusun anggaran yang tepat dan } \\
\text { realistis dalam menaksir peneriamaan } \\
\text { dan pengeluaran dana. }\end{array}$ & Sesuai & \\
\hline & & Klasifikasi transaksi & $\begin{array}{l}\text { Anggaran tahunan LKM disusun } \\
\text { berdasarkan rencana tahunan LKM } \\
\text { yang sesuai dengan prioritas kegiatan. }\end{array}$ & Sesuai & \\
\hline & & $\begin{array}{l}\text { Catat transaksi sesuai } \\
\text { nilai moneter yang } \\
\text { tepat }\end{array}$ & $\begin{array}{l}\text { Mencatat dan menyusun laporan } \\
\text { keuangan dalam satuan moneter } \\
\text { rupiah. }\end{array}$ & Sesuai & \\
\hline & & $\begin{array}{l}\text { Mencatat transaksi } \\
\text { pada periode yang } \\
\text { tepat }\end{array}$ & $\begin{array}{l}\text { Sekretariat membuat laporan } \\
\text { keuangan bulanan untuk LKM, yang } \\
\text { menjelaskan perubahan keuangan } \\
\text { dalam periode bulanan atau tahunan. }\end{array}$ & Sesuai & \\
\hline & & $\begin{array}{l}\text { Penyajian dalam } \\
\text { laporan keuangan } \\
\text { secara tepat }\end{array}$ & $\begin{array}{l}\text { Adanya pemantauan oleh LKM } \\
\text { dengan melihat saldo buku kas } \\
\text { periode berjalan harus tepat sesuai } \\
\text { dengan jumlah tunai dalam kotak kas } \\
\text { kecil. }\end{array}$ & Sesuai & \\
\hline \multirow[t]{3}{*}{5} & Pengawasan & Suvervisi yang efektif & $\begin{array}{l}\text { Adanya monitoring, evaluasi, analisis } \\
\text { dan rekomendasi perbaikan kinerja } \\
\text { LKM / UPK secara terus menerus. }\end{array}$ & Sesuai & \\
\hline & & $\begin{array}{l}\text { Akuntansi } \\
\text { pertanggung jawaban }\end{array}$ & $\begin{array}{l}\text { Menyediakan laporan keuangan yang } \\
\text { layak audit sebagai informasi dan } \\
\text { pertanggung jawaban kepada pihak } \\
\text { terkait dan menyediakan laporan } \\
\text { keuangan yang memiliki kenerja } \\
\text { pembukuan sesuai dengan standar } \\
\text { yang berlaku pada KOTAKU. }\end{array}$ & Sesuai & \\
\hline & & Pengauditan internal & $\begin{array}{l}\text { Auditor internal tidak terpisah dengan } \\
\text { LKM }\end{array}$ & Tidak sesuai & $\begin{array}{l}\text { Akan lebih besar } \\
\text { kemungkinan terjadinya } \\
\text { penyimpangan, baik } \\
\text { penyimpangan yang sifatnya } \\
\text { kepatuhan, kecurangan, } \\
\text { pekerjaan yang tidak efektif, } \\
\text { dan laporan keuangan yang } \\
\text { tidak menjelaskan kondisi } \\
\text { keuangan yang sesungguhnya. }\end{array}$ \\
\hline
\end{tabular}

Sumber : Penulis, 2018

\section{PEMBAHASAAN}

\section{Lingkungan pengendalian berdasarkan prinsip Committee of Sponsoring Organizations (COSO)}

Menurut teori COSO dalam Diana dan Setiawati (2011:83) lingkungan pengendalian harus ada pada setiap organisasi tidak perduli apakah organisasi tersebut dari perusahaan besar ataupun perusahaan kecil, harus memiliki lingkungan pengendalian yang kuat. Lingkungan pengendalian yang lemah kemungkinan besar diikuti dengan kelemahan dalam komponen pengendalian internal yang lain. Ada beberapa komponen yang mempengaruhi lingkungan pengendalian yaitu :
a. Filosofi dan gaya manajemen operasi
b. Komitmen terhadap intregritas dan nilai-nilai etika
c. Komitmen terhadap kompetensi
d. Komite audit dari dewan direksi
e. Struktur organisasi 
f. Metode penetapan otoritas dan tanggung jawab

g. Kebijakan dan praktik sumber daya manusia

Pada program KOTAKU untuk komponen lingkungan pengendalian berjalan dengan efektif, pengendalian intern terhadap pemberian kredit dana bergulir KOTAKU telah menerapkan satu komponen pengendalian yang ditetapkan COSO yaitu lingkungan pengendalian, KOTAKU sudah melakukan semua kegiatan yang terdapat di komponen lingkungan pengendalian yaitu Fasilitator yang mengembangkan berbagai sikap positif dalam berkelompok dan memantau keefektifan para petugas UPK, UPK memiliki buku pedoman dalam pengelolahan pinjaman kredit dana bergulir, adanya persyaratan yang harus dipenuhi untuk menjadi LKM, UPK, pengawas UPK, adanya auditor ekternal yang mengaudit pinjaman bergulir yaitu "kantor akuntan publik Drs. Acmad Djunaidi B. AK", struktur lengkap LKM yang mengelolah pinjaman bergulir, dan adanya uraian tugas dan tanggung jawab dari semua konsultan, pelatihan pada setiap UPK serta rekomendasi perbaikan kinerja UPK/LKM.

Penaksiran risiko berdasarkan prinsip Committee Of Sponsoring Organizations (COSO)

Menurut teori COSO dalam Diana dan Setiawati (2011:87) setiap perusahaan kecil maupun perusahaan besar pasti menghadapi risiko internal maupun ekternal dalam usahanya mencapai tujuan perusahaan. Manajemen harus mengidentifikasi paling tidak satu jenis pengendalian untuk mengatasi resiko yang mungkin dihadapi perusahaan, ada tiga jenis pengendalianyang dipilih yaitu pengendalian preventif, pengendalian detektif, dan pengendalian korektif. Berdasarkan hasil analisis ditabel 3 KOTAKU telah menerapkan pengendalian intern COSO pada komponen penaksiran risiko, KOTAKU melakukan monitoring dan penanganan pinjaman bermasalah, monitoring pinjaman bergulir bertujuan untuk meningkatkan kualitas pengelolahan dan pelayanan pinjaman bergulir dari UPK kepada KSM sehingga tujuan program pinjaman bergulir tercapai.

Kegiatan monitoring administratif dilakukan oleh Pengawas dan Manajer UPK dengan mengamati semua core indicators atau Indikator Utama yang terdiri dari 4 indikator kinerja keuangan, yaitu :

LAR : adalah indikator yang menunjukkan berapa \% peminjam yang menunggak.

PAR : adalah inidikator yang menunjukkan berapa $\%$ pinjaman yang tertunggak

ROI : adalah kemampuan UPK untuk menghasilkan laba dari modal yang digunakan untuk pinjaman bergulir.

$\mathrm{CCr} \quad$ : adalah kemampuan UPK untuk menutup biaya dari pendapatan yang diperolehnya.

Monitoring lapangan dilakukan oleh pengawas secara berkala minimal sebulan sekali dengan uji petik yang mengarah ke seluruh peminjam, apabila ditemukan kasus atau penyimpangan maka dilakukan pemeriksaan khusus untuk menyelesaikan kasus tersebut atau untuk menemukan apakah ada kasus lain disamping yang sudah diketemukan, monitoring lapangan dilakukan dengan melakukan kunjungan ke rumah atau ke lokasi usaha peminjam secara berkala sesuai dengan kebutuhan. Dalam rangka menjalin hubungan baik antara petugas UPK dengan peminjam, minimal satu bulan setelah raealisasi pinjaman petugas UPK harus mengunjungi anggota KSM peminjam, kunjungan selanjutnya tergantung pada kualitas pembayaran angsuran pinjaman yang dilakukan oleh peminjam, apabila terdapat peminjam yang pembayaran angsuran pinjamannya cenderung memburuk, maka petugas UPK harus sering mengunjungi peminjam tersebut.

Hal lain yang dilakukan KOTAKU untuk mengatasi resiko dengan melakukan pengendalian, yaitu :

a. Menagih Tunggakan

Menagih Tunggakan adalah upaya penyelesaian pinjaman bermasalah dengan melakukan kunjungan penagihan kepada peminjam yang menunggak.

b. Penyelamatan Pinjaman Bermasalah 
Berdasarkan hasil kunjungan dijumpai peminjam yang bermasalah dan memerlukan penyelamatan maka perlu upaya penyelamatan pinjaman. Penyelamatan dapat dilakukan apabila peminjam masih memiliki kemauan dan kemampuan untuk membayar angsuran pinjamannya.

Tujuan penyelamatan pinjaman adalah :

1) Agar pinjaman dapat kembali

2) Peminjam masih bisa terus memperoleh akses pinjaman ke UPK.

3) Kinerja pinjaman bergulir UPK sehat Jenis penyelamatan pinjaman bermasalah terdiri dari penjadwalan ulang (rescheduling), mensyaratkan kembali (reconditioning) atau mengatur kembali (restructuring) pinjaman yang bersangkutan.

a) Rescheduling

Rescheduling atau penjadwalan kembali adalah suatu upaya penyelamatan pinjaman yang bermasalah dengan melakukan penjadwalan ulang terhadap pembayaran kembali sisapinjaman yang masih ada.

b) Reconditioning

Reconditioning atau pensyaratan kembali adalah suatu upaya penyelamatan pinjaman bermasalah dengan melakukan pengaturan kembali mengenai besar pinjaman tanpa merubah jangka waktu pinjaman yang tersisa.

c) Restructuring

Restructuring atau pengaturan kembali adalah suatu upaya penyelamatan pinjaman bermasalah dengan melakukan pengaturan kembali mengenai besar pinjaman dan jangka waktu pembayaran kembalinya. Persyaratan untuk melakukan restructuring sama dengan persyaratan untuk pinjaman rescheduling.

c. Menagih melalui jalur hukum

Penagihan pinjaman melalui jalur hukum bukan merupakan cara penagihan yang disarankan dalam program pinjaman bergulir ini dengan pertimbangan :

1) tidak ada agunan

2) biaya terlalu mahal

3) prosesnya cukup panjang dan memakan waktu

4) harus didukung dengan bukti-bukti yang cukup.

Tapi jika masyarakat dengan LKM sepakat penyelesaian pinjaman bermasalah melalui jalur hukum tidak dipermasalahkan.

\section{Aktivitas pengendalian berdasarkan prinsip Committee Of Sponsoring Organizations (COSO)}

Pada komponen aktivitas pengendalian menurut teori COSO dalam Diana dan Setiawati (2011:88) ada lima hal pengendalian intern COSO yaitu :

a. Desain dokumen yang baik dan bernomor urut tercetak

b. Pemisahan tugas

c. Otorisasi yang memadai

d. Mengamankan harta dan catatan perusahaan

e. Menciptakan pengecekan independen atas pekerjaan karyawan lain

Pada KOTAKU aktivitas pengendaliannya belum berjalan dengan efektif, disebabkan adanya pembagian tugas yang belum benar-benar baik karena pemberi peminjam dan pemeriksa peminjam dilakukan oleh UPK sendiri, pada tahap pengajuan pinjaman KSM yang didampingi petugas UPK melengkapi semua dokumen yang diperlukan dan pada tahap pemeriksaan pinjaman UPK memeriksa kelengkapan dokumen KSM serta mencari informasi dan melakukan analisis pinjaman masing -masing anggota KSM berdasarkan 5C (character, condition, capacity, capital dan collateral), hal ini tentu tidak efektif karena UPK bisa saja melakukan tindakan kecurangan misalnya membuat hasil survey yang tidak benar agar pengajuan bisa disetujui, padahal hal ini dapat 
merugikan pinjaman bergulir KOTAKU karena nantinya sangat memungkinkan KSM tidak mampu membayar ansurannya dan menimbulkan kredit macet.

Selain itu Pengecekan independen yang hanya untuk mengaudit pinjaman bergulir saja bukan untuk mengaudit para konsultan KOTAKU padahal pengecekan independen ini sangat diperlukan untuk melihat apakah para konsultan KOTAKU dan para UPK telah melakukan kecurangan dan apakah pengendalian intern KOTAKU sudah dilaksakan atau belum.

Namun pada poin pemberian otorisasi yang memadai sudah baik, karena terbukti pada tahap putusan (persetujuan/penolakan) pinjaman UPK memiliki wewenang menandatanggani dalam kolom tanda tangan persetujuannya, pada poin mengamankan harta dan catatan perusahaan KOTAKU telah mengamankan catatan dan dokumen nasabah untuk tidak di publikasikan dan sekretariat LKM yang memelihara catatan semua aset selalu terbarui dan melakukan pengecekan secara rutin untuk memastikan pengamanannya.

\section{Informasi dan komunikasi berdasarkan prinsip Committee Of Sponsoring Organizations (COSO)}

Menurut teori COSO dalam Diana dan Setiawati (2011:90) informasi harus diidentifikasi, diproses, dan didokumentasikan kepersonil yang tepat sehingga setiap orang dalam perusahaan dapat melaksankan tanggung jawab mereka yang baik. Sistem informasi akuntansi harus bisa menghasilkan laporan keuangan yang handal, tujuan utama sistem informasi akuntansi yaitu :

a. Mengidentifikasi dan mencatat semua transaksi yang valid

b. Mengklasifikasikan transaksi sebagaimana seharusnya

c. Mencatat transaksi sesuai dengan dengan nilai moneter yang tepat

d. Mencatat transaksi pada periode akuntansi yang tepat

e. Menyajikan transaksi dan pengungkapan terkait dalam laporan keuangan secara tepat.

Pada KOTAKU Informasi dan komunikasi mengenai pinjaman bergulir

KOTAKU sudah berjalan dengan efektif berdasarkan prinsip COSO hal ini dapat dilihat dengan adanya setiap tahun akuntansi dan LKM dibantu oleh sekretariat harus menyusun anggaran yang tepat dan realistis dalam menaksir peneriamaan dan pengeluaran dana, anggaran tahunan LKM disusun berdasarkan rencana tahunan LKM yang sesuai dengan prioritas kegiatan, mencatat dan menyusun laporan keuangan dalam satuan moneter rupiah, sekretariat membuat laporan keuangan bulanan untuk LKM, yang menjelaskan perubahan keuangan dalam periode bulanan atau tahunan, dan adanya pemantauan oleh LKM dengan melihat saldo buku kas periode berjalan harus tepat sesuai dengan jumlah tunai dalam kotak kas kecil

\section{Pengawasan berdasarkan prinsip Committee Of Sponsoring Organizations (COSO)}

Menurut teori COSO dalam Diana dan Setiawati (2011:91) kegiatan utama dalam pengawasan kinerja, yaitu :

a. Supervise yang efektif

b. Akuntansi pertanggung jawaban

c. Pengauditan internal

Berdasarkan hasil analisis KOTAKU belum menerapkan pengendalian intern COSO pada komponen pemantauan, KOTAKU mempunyai auditor internal tapi tidak terpisah dengan LKM hal itu mungkin akan menimbulkan adanya kerjasama antar LKM dan akan berkemungkinan besar terjadinya penyimpangan, baik penyimpangan yang sifatnya kepatuhan, kecurangan, pekerjaan yang tidak efektif, dan laporan keuangan yang tidak menjelaskan kondisi keuangan yang sesungguhnya. Namun pada unsur-unsur pengendalian intern COSO supervisi yang aktif dan akuntansi pertanggung jawaban KOTAKU sudah efektif terbuki adanya monitoring, evaluasi, analisis dan rekomendasi 
perbaikan kinerja LKM/UPK secara terus menerus dan menyediakan laporan keuangan yang layak audit sebagai informasi dan pertanggung jawaban kepada pihak terkait dan menyediakan laporan keuangan yang memiliki kenerja pembukuan sesuai dengan standar yang berlaku pada KOTAKU.

\section{PENUTUP}

\section{Simpulan}

Sistem pemberian kredit pinjaman bergulir yang dilaksanakan KOTAKU sudah memenuhi unsur-unsur pengendalian intern menurut COSO, kecuali komponen aktivitas pengendalian pada unsur pemisahan tugas yaitu pemberi pinjaman tidak terpisah dengan pemeriksa pinjaman, dan komponen pengawasan pada unsur pengauditan internal yaitu auditor internal yang tidak terpisah dengan LKM.

\section{Rekomendasi}

Terdapat ketidaksesuaian antara unsur-unsur pengendalian intern menurut COSO dengan pengendalian intern pemberian kredit pada pinjaman bergulir KOTAKU peneliti merekomendasikan, sebaiknya pengendalian intern menurut COSO yang belum diterapkan sebaiknya dilakukan untuk memperlancar pemberian kredit seperti :

1) Pemisahan tugas antara pemberi dan pemeriksaan pinjaman

2) Pengauditan internal seharusnya auditor internal dipisahkan dengan petugas LKM agar tidak adanya kolusi dan penyimpangan.

\section{DAFTAR PUSTAKA}

Abdullah Thamrin dan Tantri Francis, 2014, Bank dan Lembaga Keuangan, Cetakan Ke3 Penerbit Raja Grafindo, Jakarta.

Diana Anatasia dan Setiawati Lilies, 2011, Sistem Informasi Akuntansi, Penerbit Andi Yogyakarta, Jogyakarta.

Hairun Nisa, 2017, Analisis Sistem Pengendalian Intern Persetujuan Kredit Dalam Memperkecil Resiko Piutang Tidak Tertagih pada PT Nusa Surya Ciptadana Cabang Martapura, Jurnal Ilmiah Ekonomi Bisnis, ISSN : 2442-4560, Vol 3, No 1.

Hasibuan, SP Malayu, 2005, Manajemen Sumber Daya Manusia, Penerbit Bumi Aksara, Jakarta

Kasmir, 2015, Analisis Laporan Keuangan, Penerbit Rajawali Press, Jakarta

Kasmir, 2016, Analisis Laporan Keuangan, Penerbit Raja Grafindo, Jakarta

Krismiaji, 2015, Sistem Informasi Akuntansi, Edisi Ke 4, STIE YKPN, Yogyakarta

Penta Widyartati, 2016, Faktor Faktor Yang Mempengaruhi Pinjaman Macet Dana Bergulir di BKM Sedang Mukti Kelurahan Sendangguwo Kota Semarang, Jurnal Ilmiah, ISSN :2085-5656, Vol 8 No. 3.

Siti Nuraini, 2016, Penanganan Tunggakan Dana Bergulir (NPL) Pasca Pelaksanaan PNPM Mandiri, Jurnal Ilmiah, ISSN 2548-1401, Vol 1

Sujarweni Wiratna, 2015, Metode Penelitian Bisnis dan Ekonomi, Cetakan Ke 1, Penerbit Pustaka Baru Press, Yogyakarta

Sugiyono, 2013, Metode Penelitian Kuantitatif, Kualitatif, dan R\&D, Cetakan Ke 19, Penerbit Alfabeta, Bandung

William Owusu-Boateng, Richard Amofa dan Isaac Osei Owusu, 2017, The Internal Control Systems of GN Bank Ghana British, Journal Of Economic, Management, and Trade, Vol 8.

Yesti Nawangsari dan Iwan Setya Putra, 2016, Analisis SPI Pemberian Kredit Dalam Menurunkan Tingkat Kredit Macet Pada KSP, Jurnal Kompilek, Vol 8, No 1. 